\title{
Degradation studies and thermodynamic parameters in aqueous solution of chemotherapeutic agents: Daunorubicin, doxorubicin and vincristine
}

\author{
Nurgül KARADAŞ BAKIRHAN 1 * (D), Bediha AKMEŞE 2 (D), Tuğce GÖVER ${ }^{3}$ (D), \\ Hamideh IMANZADEH 4,5 (D), Sibel A. ÖZKAN $5 *$ (D) \\ 1 University of Health Sciences, Gulhane Faculty of Pharmacy, Department of Analytical Chemistry, Ankara, Turkey \\ 2 Department of Chemistry, Faculty of Arts and Sciences, Hitit University, Çorum, Turkey \\ 3 Department of Analytical Chemistry, Faculty of Pharmacy, Selçuk University, Konya, Turkey \\ 4 Department of Chemistry, Faculty of Sciences, Azarbaijan Shahid Madani University, Tabriz, Iran \\ 5 Department of Analytical Chemistry Ankara University, Faculty of Pharmacy, Ankara, Turkey \\ * Corresponding Authors. E-mail: ozkan@pharmacy.ankara.edu.tr (S.A.Ö.); nurgulk44@gmail.com (N.K.B.); Tel. +90- \\ 312-203 3181.
}

Received: 27 July 2019 / Revised: 31 August 2019 / Accepted: 02 September 2019

\begin{abstract}
The degradation of daunorubicin (DNR), doxorubicin (DXR) and vincristine (VCR) as chemotherapeutic agents was investigated under stress conditions such as acidic and alkaline media, oxidation, photolytic and heating. The degradation pathway determined by high-performance liquid chromatography (HPLC). Daunorubicin, doxorubicin and vincristine completely disintegrated in the basic medium. It has been determined that these drugs are resistant to heat. Daunorubicin and doxorubicin are resistant to UV light. However, vincristine is not very stable such as the other two compounds against UV light. The kinetic and thermodynamic parameters of daunorubicin, doxorubicin and vincristine were investigated in neutral media with different temperatures by electrochemical technique. Enthalpy, entropy and Gibbs free energy parameters were investigated in $\mathrm{pH} 7.4$ phosphate buffer (PB) solution due to stability of these drugs at this $\mathrm{pH}$. The studied chemotherapeutic agents showed endothermic process on glassy carbon-based electrode surface. Daunorubicin, doxorubicin and vincristine showed strongly adsorption process in room temperature. However, it showed diffusion property from electrode to solution with increasing the temperature values.
\end{abstract}

KEYWORDS: Degradation; liquid chromatography; drug stability; chemotherapeutic agent; temperature effect.

\section{INTRODUCTION}

Stress tests have various degradation mechanisms such as photolytic, hydrolytic, oxidative, and heat degradation. To achieve the desired level of degradation, the exposure to oxidizing, acid or base agent concentration and exposure to conditions such as heat, light may be changed [1]. Drug products may deteriorate during manufacture, application and storage, as many of the drugs are sensitive to light [2,3]. The photostability of a drug is its response when exposed to the solar, UV, and visible light. There are many purposes of photostability studies such as internal structural properties of photostability, the physical and chemical changes caused by light effects, formation of photodegradation methods and mechanisms, the shelf life of the products, the light-induced biological effects, the change in formulation parameters, take precautions against negative situations that may occur during production, packaging, labelling, transportation and storage when exposed to light [4]. In this work, the degradation and stabilization of vincristine, daunorubicin and doxorubicin under different conditions were studied using the HPLC method.

Vincristine (Figure 1a), daunorubicin (Figure 1b) and doxorubicin (Figure 1c) are used in the wipe out of some species of cancer. Vincristine, a chemotherapeutic agent, is widely used in the treatment of solid tumours and acute leukaemia $[5,6]$. VCR has a great effect against Wilms' tumour, various lymphomas, acute leukaemia and rhabdomyosarcoma. The metabolic products and / or degradation products of the VCR can cause toxicity and antitumor [7].

How to cite this article: Karadaş Bakırhan N, Akmeşe B, Göver T, Imanzadeh H, Özkan SA. Degradation studies and thermodynamic parameters in aqueous solution of chemotherapeutic agents: Daunorubicin, doxorubicin and vincristine. J Res Pharm. 2019; 23(5): 822-831. 


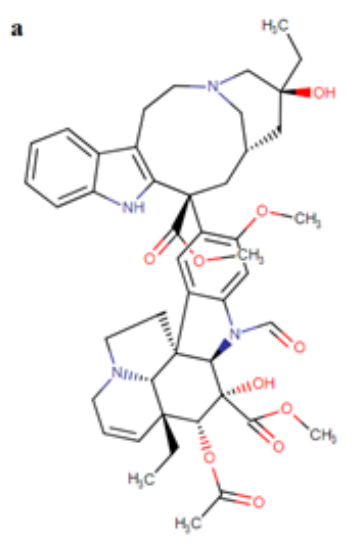

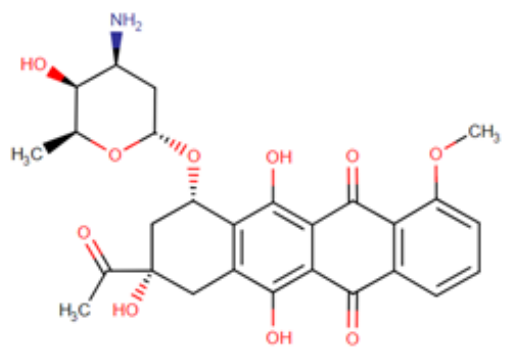<smiles>COc1cccc2c1C(=O)c1c(O)c3c(c(O)c1C2=O)C[C@@](O)(C(=O)CO)C[C@@H]3O[C@H]1C[C@H](N)[C@@H](O)[C@H](C)O1</smiles>

Figure 1. Structures of a) vincristine, b) daunorubicin and c) doxorubicin.

Daunorubicin is a cytotoxic agent used to protect against cancer cells. DNR is used for the treatment of many diseases such as Kaposi's sarcoma, acute lymphocytic leukaemia (ALL), chronic myelogenous leukaemia (CML) and acute myeloid leukaemia (AML) [8]. Doxorubicin, a hydroxylated similar of daunorubicin, is a natural anthracycline derivative. Doxorubicin is used for the treatment of many diseases such as neuroblastoma, Hodgkin's and non-Hodgkin's lymphomas, acute lymphoblastic leukaemia, soft tissue and bone sarcomas, transitional cell bladder carcinoma, breast carcinoma, bronchogenic carcinoma, ovarian carcinoma, gastric carcinoma, and thyroid carcinoma [9-11].

Activation energy $\left(E_{a}\right)$, enthalpy $(\Delta H)$, entropy $(\Delta S)$ and Gibbs free energy $(\Delta G)$ are important parameters may help to explain the drug release from delivery systems. The changes in the thermodynamic parameters show drug release behavior, which are, at least, under the influence of the surrounding environment and the type of system. An enthalpy suggests that all systems present release processes of an endothermic nature $(\Delta H>0)$ or exothermic nature $(\Delta H<0)$ [12]. The systems' entropy is negative $(\Delta S<0)$, which characterizes a decrease in the system disorder, once the drug diffuses in the medium to try to reach an equilibrium between the amount inside and outside of the drug delivery [12]. In other way, entropy is positive $(\Delta S>0)$ which characterizes a increase in the system disorder. The thermodynamic of the reaction process is correlated to the variations in the $\Delta G$, the most important thermodynamic parameter associated with the release kinetics [13]. Furthermore, $\Delta G$ reveals the spontaneity of the process when a negative value is calculated for this parameter. The positive $\Delta G(\Delta G>0)$ shows non-spontaneous natural process [14].

Electrochemistry is very common method in analytical applications. The redox behavior and sensitive and rapid analysis of many electroactive compounds can be studied with this method. Our aim is to investigate physicochemical features of chemotherapeutic agents in neutral aqueous solutions. Up to date, no report found on the kinetic and thermodynamic parameters of daunorubicin, doxorubicin and vincristine by electrochemical methods.

\section{RESULTS AND DISCUSSION}

\subsection{Degradation studies}

The stress conditions employed for the degradation study included acid hydrolysis, base hydrolysis, oxidation, photolytic condition, and heating in the oven (at $100^{\circ} \mathrm{C}$ ). For the hydrolytic and oxidative degradation studies, the solutions were prepared by dissolving the drugs directly in deionized water and then diluted with hydrogen peroxide, sodium hydroxide or hydrochloric acid solution, to achieve a concentration of $100 \mu \mathrm{g} \mathrm{mL}^{-1}$ for each solution.

Acid, base and oxidation conditions were applied at room temperature during 2 hours. However, drugs could not degrade at this condition. Heating procedure is very practical pathway to investigate drugs behavior at acid, base and oxidation solutions [15,16,17]. Hence, further studies were applied at $75^{\circ} \mathrm{C}$ during $30 \mathrm{~min}$. Acid and alkaline hydrolysis of drug substance in solution state was conducted with $1.0 \mathrm{M} \mathrm{HCl}$ and $1.0 \mathrm{M}$ $\mathrm{NaOH}$ at $75^{\circ} \mathrm{C}$ during $30 \mathrm{~min}$. Sample solutions of drug substance and drug product were kept in $3 \%$ hydrogen peroxide at $75^{\circ} \mathrm{C}$ during $30 \mathrm{~min}$ for oxidative stress. Thermal and photo-degradation of drug substances carried out in solid state. After the degradation, the stock solutions were prepared by dissolving in deionized water to achieve a concentration of $100 \mu \mathrm{g} \mathrm{mL}-1$. For photolytic stress, drug samples as the solid state, was 
irradiated with UV radiation having peak intensities at $360 \mathrm{~nm}$ for 6 and $24 \mathrm{~h}$. For thermal stress, DNR, DXR and VCR put in a controlled-temperature oven at $100^{\circ} \mathrm{C}$ for 6 and $24 \mathrm{~h}$.

Area values were found by injection from DNR, DXR and VCR standards at $100 \mu \mathrm{g} \mathrm{mL}^{-1}$ concentration into the system. Percent degradation values were calculated by comparing the area values of the standard compounds of $100 \mu \mathrm{g} \mathrm{mL}^{-1}$ with area values of degradation products. These results given in Table 1 . Chromatograms obtained from the degradation studies for DNR, DXR and VCR were given in Figure 2, Figure 3 and Figure 4.

Table 1. The percent degradation values calculated for DNR, DXR and VCR.

\begin{tabular}{|c|c|c|c|}
\hline Stress conditions & $\begin{array}{l}\text { Degradation of } \\
\text { DNR\% }\end{array}$ & $\begin{array}{l}\text { Degradation of } \\
\text { DXR\% }\end{array}$ & $\begin{array}{l}\text { Degradation of } \\
\text { VCR } \%\end{array}$ \\
\hline $\mathrm{HCl}(1.0 \mathrm{M})$ & 96.37 & 30.39 & 65.20 \\
\hline $\mathrm{NaOH}(1.0 \mathrm{M})$ & 100 & 100 & 100 \\
\hline $\mathrm{H}_{2} \mathrm{O}_{2}(3 \%)$ & 86.52 & - & 90.72 \\
\hline UV (6 h) & 1.49 & 2.75 & 9.67 \\
\hline UV (24 h) & 2.25 & 3.78 & 34.78 \\
\hline Heating (100 oC 6 h) & 1.31 & 0.08 & 0.45 \\
\hline Heating (100 oC 24 h) & 13.17 & 0.51 & 7.76 \\
\hline
\end{tabular}

\subsection{Physicochemical parameters of DNR, DXR and VCR}

Electrooxidation of $0.1 \mathrm{mM}$ DNR (anodic response at $0.5 \mathrm{~V}$ ), $0.1 \mathrm{mM}$ DXR (anodic response at $0.45 \mathrm{~V}$ ) and $0.1 \mathrm{mM}$ VCR (anodic response at $0.65 \mathrm{~V}$ ) onto glassy carbon electrode (GCE) studied in pH 7.4 PB solution by at various temperatures of 298, 303, 308 and $313 \mathrm{~K}$ for the determination of thermodynamic features. Anodic responses of DNR, DXR and VCR peaks increased with the increasing of temperature (Figure 5).

The kinetic rate constants $\left(\mathrm{k}_{\mathrm{s}}\right)$ calculated at different temperatures by following equation (Table 2):

$I_{p}=n F A k_{s} C$

The values of $\Delta \mathrm{G}$ evaluated from $\mathrm{k}_{\mathrm{s}}$ using equation 2 (Table 2).

$\Delta G=5778.8\left(5.096-\log k_{s}\right)$

The Arrhenius equation $k_{s}=A e^{\frac{-E a}{R T}}$ applied for the calculation of activation energy $\left(\mathrm{E}_{\mathrm{a}}\right)$. The values of $E_{a}$ acquired from the slope of the $\log k_{s} v s .1 / T$ plot inserted into equation $(3,4)$ for the evaluation of enthalpy $(\Delta \mathrm{H})$ and entropy $(\Delta \mathrm{S})$, respectively.

$$
\begin{aligned}
\Delta H^{*} & =E_{a}-R T \\
\Delta S^{*} & =\frac{\Delta H^{*}-\Delta G^{*}}{T}
\end{aligned}
$$

An examination of exposes a decrease in $\Delta H$ and $\Delta S$ with increasing temperature. $\mathrm{k}_{\mathrm{s}}$ and $\Delta \mathrm{G}$ increased with increasing in temperature.

The decreasing of $\Delta \mathrm{G}$ with rise in temperature shows the redox process to become more facile at higher temperature values. The positive $\Delta \mathrm{H}$ of activation suggests the endothermic nature of the electrode process, while negative $\Delta S$ of activation can be attributed to the adsorptive characteristic of the oxidized product of the analyte. The decrease in $\Delta S$ with increasing temperature suggests the trend toward diffusivity of the oxidized product of DNR, DXR and VCR from the electrode surface. 

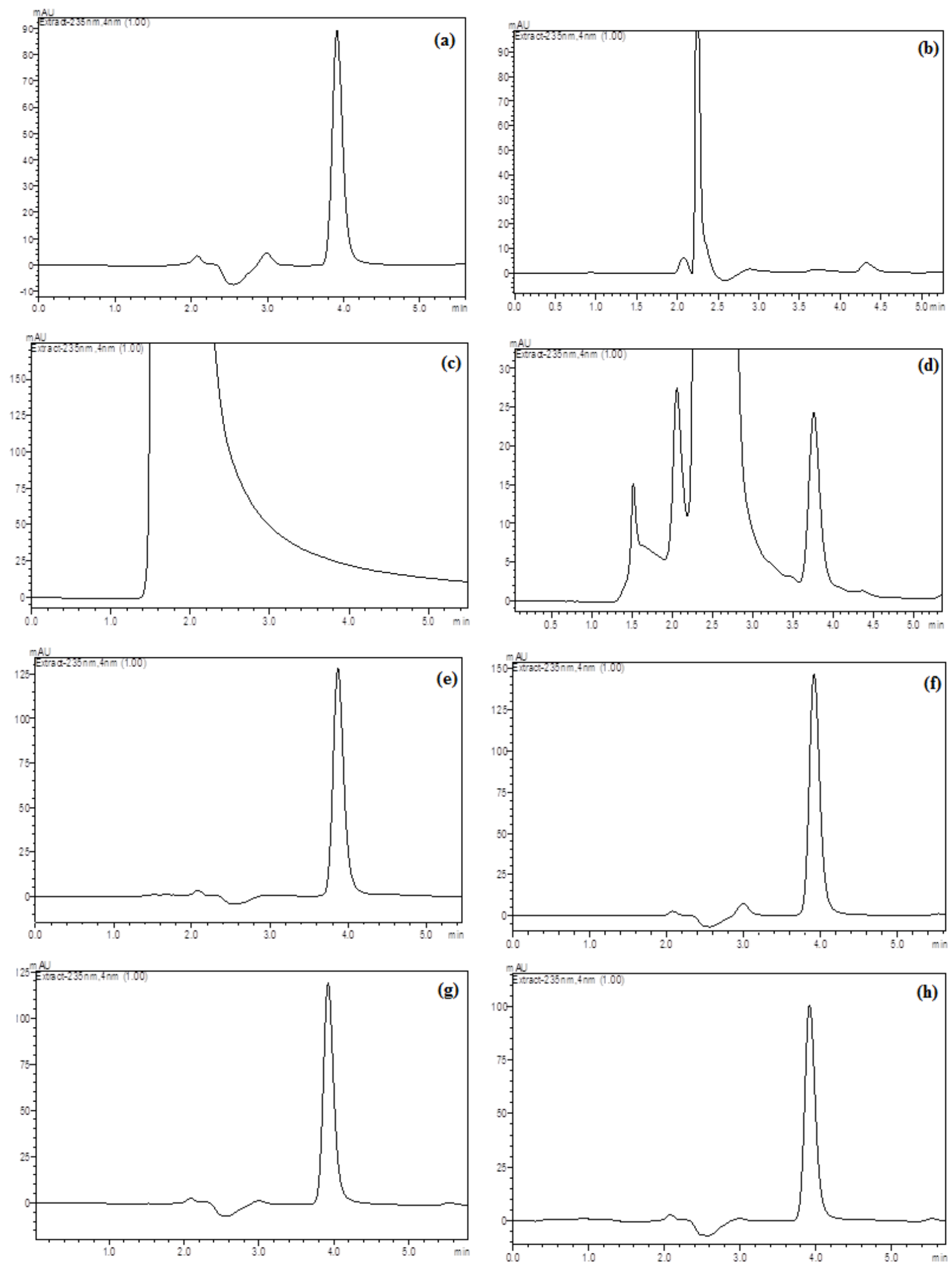

Figure 2. Typical LC chromatograms of DNR under drastic stressed conditions: (a) $100 \mu \mathrm{g} \mathrm{mL} \mathrm{m}^{-1} \mathrm{DNR}$, (b) 1.0 $\mathrm{M} \mathrm{HCl}$ at $75^{\circ} \mathrm{C}$ after $30 \mathrm{~min}$, (c) $1.0 \mathrm{M} \mathrm{NaOH}$ at $75{ }^{\circ} \mathrm{C}$ after $30 \mathrm{~min},\left(\right.$ d) $\mathrm{H}_{2} \mathrm{O}_{2} 3 \%$ at $75^{\circ} \mathrm{C}$ after $30 \mathrm{~min}$, (e) in UV light $(360 \mathrm{~nm})$ after $6 \mathrm{~h},(\mathbf{f})$ in UV light $(360 \mathrm{~nm})$ after $24 \mathrm{~h},(\mathrm{~g})$ at $100{ }^{\circ} \mathrm{C}$ after $6 \mathrm{~h}$ and $(\mathbf{h})$ at $100^{\circ} \mathrm{C}$ after $24 \mathrm{~h}$. 

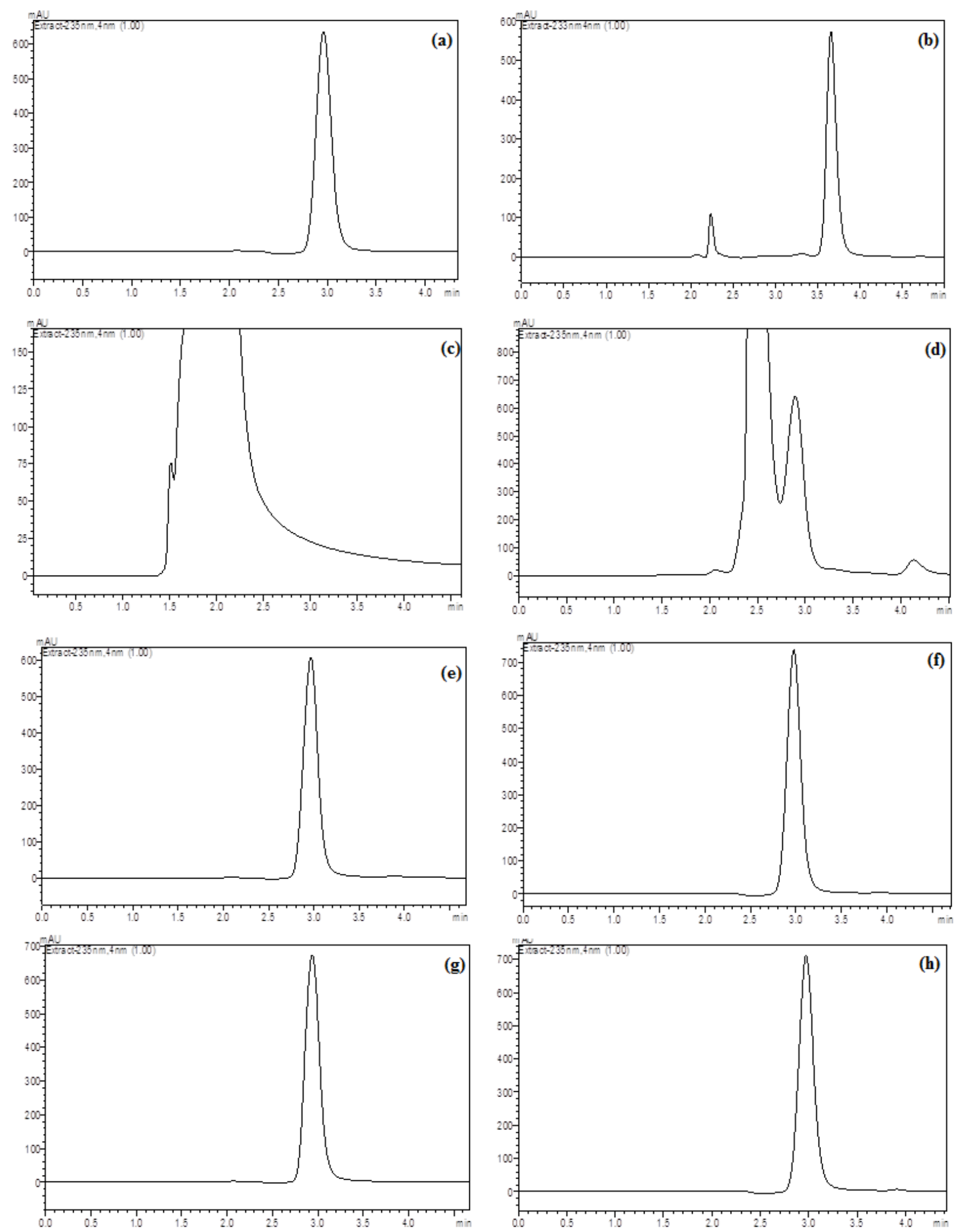

Figure 3. Typical LC chromatograms of DXR under drastic stressed conditions: (a) $100 \mu \mathrm{g} \mathrm{mL}-1$ DXR, (b) 1.0 $\mathrm{M} \mathrm{HCl}$ at $75^{\circ} \mathrm{C}$ after $30 \mathrm{~min},(\mathbf{c}) 1.0 \mathrm{M} \mathrm{NaOH}$ at $75 \circ \mathrm{C}$ after $30 \mathrm{~min}$, (d) $\mathrm{H}_{2} \mathrm{O}_{2} 3 \%$ at $75^{\circ} \mathrm{C}$ after $30 \mathrm{~min}$, (e) in UV light $(360 \mathrm{~nm})$ after $6 \mathrm{~h},(\mathbf{f})$ in UV light $(360 \mathrm{~nm})$ after $24 \mathrm{~h},(\mathrm{~g})$ at $100^{\circ} \mathrm{C}$ after $6 \mathrm{~h}$ and $(\mathrm{h})$ at $100^{\circ} \mathrm{C}$ after $24 \mathrm{~h}$. 

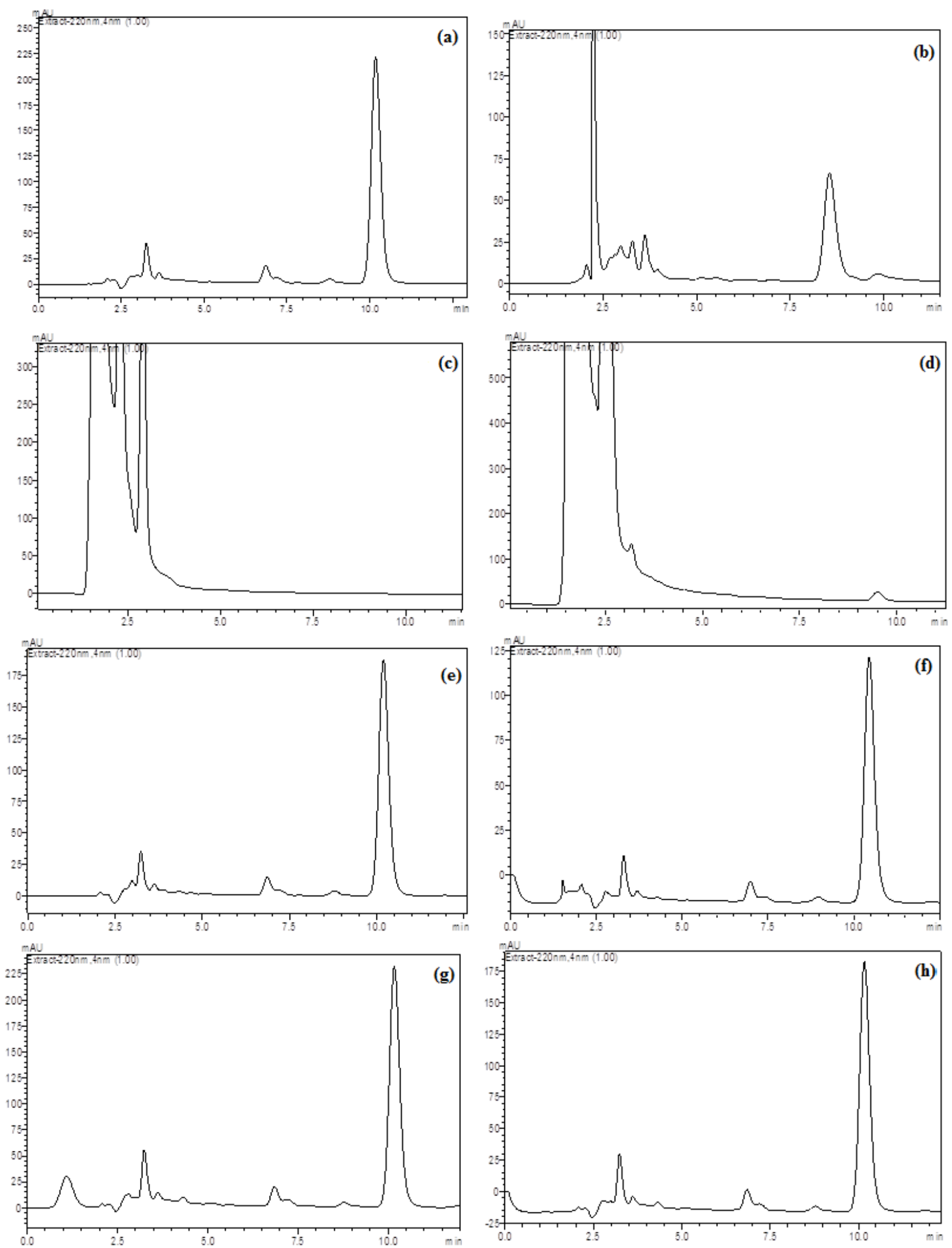

Figure 4. Typical LC chromatograms of VCR under drastic stressed conditions: (a) $100 \mu \mathrm{g} \mathrm{mL} \mathrm{L}^{-1} \mathrm{VCR}$, (b) 1.0 $\mathrm{M} \mathrm{HCl}$ at $75^{\circ} \mathrm{C}$ after $30 \mathrm{~min},(\mathbf{c}) 1.0 \mathrm{M} \mathrm{NaOH}$ at $75^{\circ} \mathrm{C}$ after $30 \mathrm{~min},\left(\right.$ d) $\mathrm{H}_{2} \mathrm{O}_{2} 3 \%$ at $75^{\circ} \mathrm{C}$ after $30 \mathrm{~min},(\mathbf{e})$ in UV light $(360 \mathrm{~nm})$ after $6 \mathrm{~h}$, (f) in UV light $(360 \mathrm{~nm})$ after $24 \mathrm{~h}(\mathrm{~g})$ at $100^{\circ} \mathrm{C}$ after $6 \mathrm{~h}$ and (h) at $100^{\circ} \mathrm{C}$ after 24 h. 

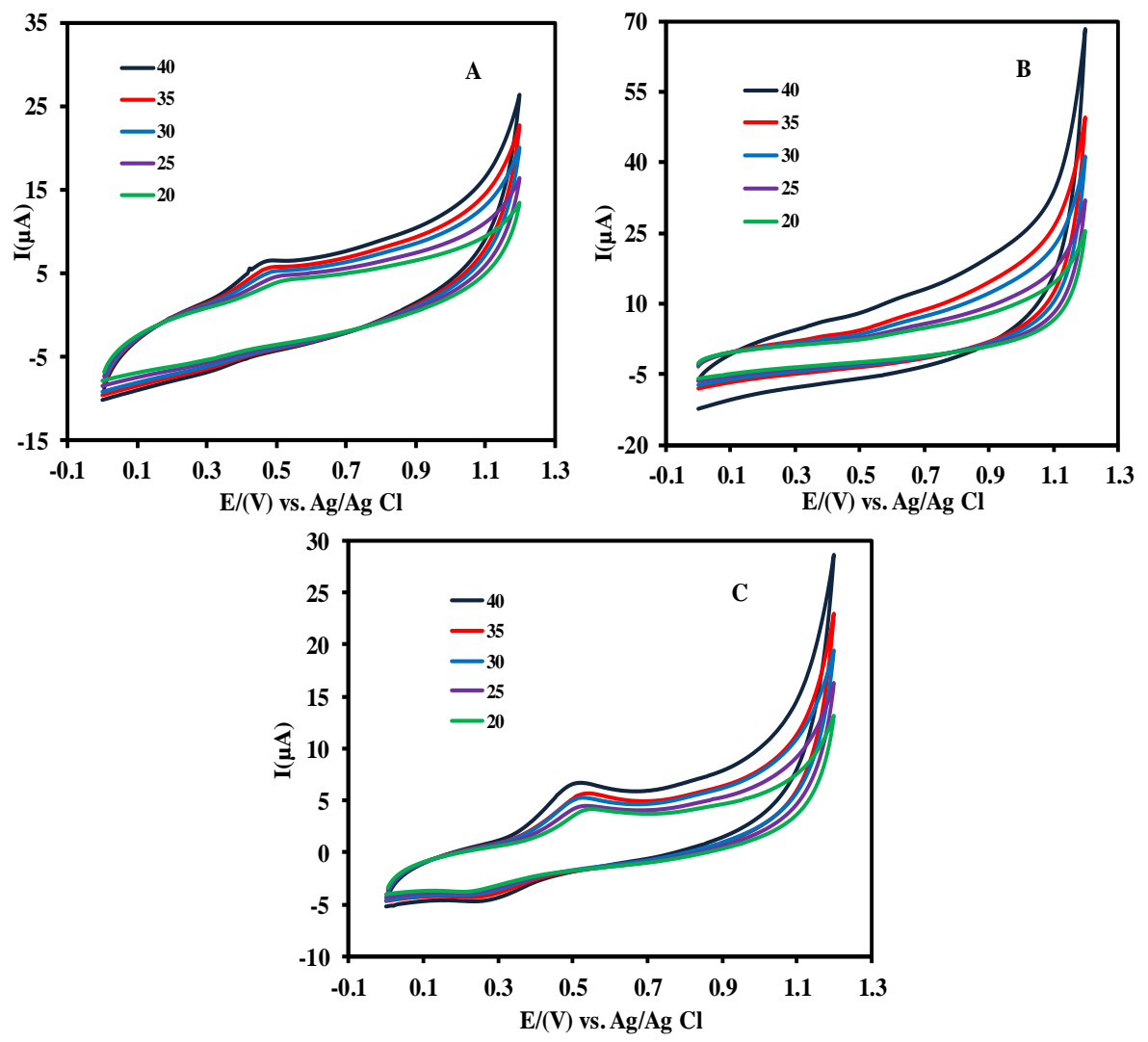

Figure 5. Cyclic voltammograms of 0.1 mM DXR (A), VCR (B) and DNR (C) in pH 7.4 PB solution at different temperatures $\left(20,25,30,35,40^{\circ} \mathrm{C}\right)$ with GCE.

Table 2. Kinetic rate constant values of DNR, DXR and VCR at different temperatures.

\begin{tabular}{ccccc}
\hline \multirow{2}{*}{$\mathbf{T}(\mathbf{K})$} & \multirow{2}{*}{$1 / \mathrm{T}\left(\mathrm{k}^{-1}\right)$} & DNR & DXR & VCR \\
\cline { 3 - 5 } & & $\mathrm{k}_{\mathrm{s}}\left(\times 10^{-5}\right)$ & $\mathrm{k}_{\mathrm{s}}\left(\times 10^{-5}\right)$ & $\mathrm{k}_{\mathrm{s}}\left(\times 10^{-5}\right)$ \\
\hline $\mathbf{2 9 3}$ & 0.00341 & 133 & 53.1 & 2.22 \\
$\mathbf{2 9 8}$ & 0.00336 & 166 & 69.1 & 3.99 \\
$\mathbf{3 0 3}$ & 0.00330 & 201 & 86.0 & 5.99 \\
$\mathbf{3 0 8}$ & 0.00325 & 225 & 103 & 7.18 \\
$\mathbf{3 1 3}$ & 0.00320 & 276 & 130 & 9.25 \\
\hline
\end{tabular}

\section{CONCLUSION}

When the studies on the degradation of the working compounds are examined, it was seen that DNR completely disintegrated in the basic medium and largely disintegrated in the acidic and peroxide medium. However, it has been determined that it is resistant to heat and UV light. It seems that DXR is completely degraded in basic medium, some in acidic medium. In the peroxide medium, the field value could not be determined due to the overlap of the DXR peak with the peroxide peak. However, it has been determined that it is resistant to heat and UV light. VCR is completely degraded in basic medium. According to the obtained results, the major part of VCR disintegrated in the peroxide medium. About more than half of VCR disintegrated in the acidic medium. It is not very stable such as the other two compounds against UV light. It has been determined that it is resistant to heat. Thermodynamic properties of three compound have been investigated in details with changing temperatures. Adsorption process is occurred at room temperature but, diffusion process began with increasing temperatures. These parameters are very important for drug release studies with nanomaterials. The kinetic profile of a drug can affect from temperature changes. The pharmacological answer of the drug might be affected, as a slower or faster release would change the drug plasmatic concentrations. In this study, we could show DNR, DXR and VCR behavior at changing temperatures at neutral solution. 
Table 3. Thermodynamic parameters of the electrooxidation process of DNR, DXR and VCR.

\begin{tabular}{|c|c|c|c|c|c|}
\hline Compounds & $\begin{array}{c}\text { Temperature } \\
\text { (K) }\end{array}$ & $\begin{array}{c}E_{a} \\
\left(k^{\prime} \text { mol-1 }^{-1}\right)\end{array}$ & $\begin{array}{c}\Delta \mathrm{G} \\
(\mathrm{kJ} \mathrm{mol}-1)\end{array}$ & $\begin{array}{c}\Delta H \\
\left(\mathrm{~kJ} \mathrm{~mol}^{-1}\right)\end{array}$ & $\begin{array}{c}\Delta S \\
\left(\mathrm{~J} \mathrm{~K}^{-1} \mathrm{~mol}^{-1}\right)\end{array}$ \\
\hline \multirow[t]{5}{*}{ DNR } & 293 & 11.67 & 46.1 & 9.23 & -125.7 \\
\hline & 298 & & 45.5 & 9.19 & -121.9 \\
\hline & 303 & & 45.0 & 9.15 & -118.4 \\
\hline & 308 & & 44.8 & 9.11 & -115.7 \\
\hline & 313 & & 44.2 & 9.07 & -112.4 \\
\hline \multirow[t]{5}{*}{ DXR } & 293 & 14.53 & 48.4 & 12.1 & -123.8 \\
\hline & 298 & & 47.7 & 12.05 & -119.7 \\
\hline & 303 & & 47.2 & 12.01 & -116.0 \\
\hline & 308 & & 46.7 & 11.97 & -112.8 \\
\hline & 313 & & 46.1 & 11.93 & -109.2 \\
\hline \multirow[t]{5}{*}{ VCR } & 293 & 22.9 & 56.3 & 20.46 & -122.4 \\
\hline & 298 & & 54.9 & 20.42 & -115.6 \\
\hline & 303 & & 53.8 & 20.38 & -110.5 \\
\hline & 308 & & 53.4 & 20.34 & -107.3 \\
\hline & 313 & & 52.8 & 20.30 & -103.7 \\
\hline
\end{tabular}

\section{MATERIALS AND METHODS}

\subsection{Chemicals and reagents}

All reagents and solvents were analytical grade and used with no further purification. DXR, VCR, and DNR were from Sigma. HPLC grade acetonitrile (ACN) was purchased from Merck (Darmstadt, Germany). Orthophosphoric acid (85\%, d:1.71 $\mathrm{g} \mathrm{mL}^{-1}$ ) was obtained from Merck (Darmstadt, Germany). Sodium hydroxide, hydrochloric acid $\left(37 \%\right.$, d:1.19 $\left.\mathrm{g} \mathrm{mL}^{-1}\right)$ and hydrogen peroxide $\left(35 \%, \mathrm{~d}: 1.13 \mathrm{~g} \mathrm{~mL}^{-1}\right)$ were supplied from Riedel-de Haen (Seelze, Germany). Ultra-pure water was produced in the laboratory with conductivity $18.21 \mathrm{~S} \mathrm{~cm}^{-1}$ was obtained using a Zeneer Power I water system (Human Corp. Korea) and pure water was used to preparation of all aqueous solutions. Phosphate buffer solution was prepared with sodium phosphate dibasic heptahydrate and sodium phosphate monobasic monohydrate in bidistilled water. $0.1 \mathrm{mM}$ drug solutions were prepared with $\mathrm{pH}$ 7.4 phosphate buffer solutions.

\subsection{Apparatus and conditions}

HPLC was achieved on a Shimadzu HPLC system (Kyoto, Japan) with a pump (LC-20 AD), a DAD detector system (SPD-M 20A), and column oven (CTO 20 AC). The separation was done on a X-Terra RP-18 $(250 \times 4.60 \mathrm{~mm} \mathrm{ID} \times 5 \mu)($ Waters Corp., Milford, MA, USA).

The mobile phase is $15 \mathrm{mM}$ o-phosphoric acid in this study. The elution performed on isocratic solvent system using this mobile phase. The mobile phase was prepared as $\mathrm{pH} 9.5$ using $1 \mathrm{M} \mathrm{NaOH}$. The flow rate was set at $1.5 \mathrm{~mL} \mathrm{~min}^{-1}$ with controlled temperature at $30^{\circ} \mathrm{C}$ [12]. DAD detector was set at the wavelength of $235 \mathrm{~nm}$ for DXR and DNR and $220 \mathrm{~nm}$ for VCR and injection volume was $20 \mu \mathrm{L}$ for every sample.

Kinetic studies performed with electrochemical analyser 'PalmSens5.2' at changing temperatures (in $\mathrm{pH}$ 7.4 phosphate buffer solution). Glassy carbon, $\mathrm{Ag} / \mathrm{AgCl}$ and platinum as working, reference and counter electrodes, respectively. Cyclic voltammetry was applied between 0 and $1.7 \mathrm{~V}$ with $0.1 \mathrm{mV} / \mathrm{s}$ scan rate.

\subsection{Stock and working solutions of standard compound}

Standard stock solutions of drugs $\left(200 \mu \mathrm{g} \mathrm{mL}^{-1}\right)$ were prepared by dissolving for each drug in ultra-pure water and stored at $+4^{\circ} \mathrm{C}$. 


\subsection{Stress testing}

\subsubsection{Acid hydrolysis}

There is an optimum $\mathrm{pH}$ value, which each material is stable. The drug changes at outside of this $\mathrm{pH}$. This change can be in the form of degradation and hydrolysis of the molecule. Solutions were prepared at concentrations of $200 \mu \mathrm{g} \mathrm{mL}^{-1}$ from DNR, DXR and VCR standards. $200 \mu \mathrm{g} \mathrm{mL}^{-1}$ of the prepared solutions were diluted to $100 \mu \mathrm{g} \mathrm{mL}-1$ by adding $1 \mathrm{M} \mathrm{HCl}$. Then, the prepared solutions put in a water bath adjusted to $75^{\circ} \mathrm{C}$ for $30 \mathrm{~min}$.

\subsubsection{Base hydrolysis}

Solutions were prepared at concentrations of $200 \mu \mathrm{g} \mathrm{mL}-1$ from DNR, DXR and VCR standards. $200 \mu \mathrm{g}$ $\mathrm{mL}^{-1}$ of the prepared solutions were diluted to $100 \mu \mathrm{g} \mathrm{mL}^{-1}$ by adding $1 \mathrm{M} \mathrm{NaOH}$. Then, the prepared solutions put in a water bath adjusted to $75^{\circ} \mathrm{C}$ for $30 \mathrm{~min}$.

\subsubsection{Oxidation}

Solutions were prepared at concentrations of $200 \mu \mathrm{g} \mathrm{mL}-1$ from DNR, DXR and VCR standards. $200 \mu \mathrm{g}$ $\mathrm{mL}^{-1}$ of the prepared solutions were diluted to $100 \mu \mathrm{g} \mathrm{mL}^{-1}$ by adding $3 \% \mathrm{H}_{2} \mathrm{O}_{2}$. Then, the prepared solutions put in a water bath adjusted to $75^{\circ} \mathrm{C}$ for $30 \mathrm{~min}$.

\subsubsection{Photolytic condition}

$10 \mathrm{mg}$ from DNR, DXR and VCR standards were weighed and then, samples were exposed to UV light having a wavelength of $360 \mathrm{~nm}$ for 6 hours and 24 hours. Standard solutions were prepared at $100 \mu \mathrm{mL}^{-1}$ concentrations and $20 \mu \mathrm{L}$ injection was made from these solutions into the system.

\subsubsection{Heat in an oven}

$10 \mathrm{mg}$ from DNR, DXR and VCR standards weighed, and these samples put in the oven adjusted to $100^{\circ} \mathrm{C}$ for 6 hours and 24 hours. Then, using these standards, $100 \mu \mathrm{g} \mathrm{mL}-1$ solutions were prepared and $20 \mu \mathrm{L}$ solution was injected from these solutions into the HPLC system.

Acknowledgements: We would like to thanks to Dr. Omer Faruk Akmeşe (from Hitit University Osmancık Ömer Derindere Vocational School, Computer Technologies) for his supports on resolution of figures at all manuscript.

Author contributions: Concept - N.K.B., B.A.; Design - N.K.B., B.A., T.G., O.F.A.; Supervision-S.A.O., N.K.B.; Resources-T.G., B.A., N.K.B.; Materials-B.A, T.G.; Data Collection - B.A., O.F.A; Literature Search - T.G; Writing - N.K.B., T.G., S.A.O; Critical Review - B.A., T.G., S.A.O., N.K.B.

Conflict of interest statement: The authors declared no conflict of interest.

\section{REFERENCES}

[1] Rawat T, Pandey IP. Forced degradation studies for drug substances and drug products- scientific and regulatory considerations. J Pharm Sci Res. 2015; 7(5): 238-241.

[2] British Pharmacopoeia, Her Majesty's Stationery Office, London, UK, 2013.

[3] United States Pharmacopeia 29, United States Pharmacopeial Convention, Rockville, Md, USA, 2012.

[4] Ahmad I, Ahmed S, Anwar Z, Sheraz MA, Sikorski M. Photostability and photostabilization of drugs and drug products. Int J Photoenergy. 2016; 1: 1-9. [CrossRef]

[5] Henderson ES. Acute lymphoblastic leukemia. In: Gunz FW, Henderson ES. (Eds). William Domashek and Frederick Gunz's leukemia. New York, Grune \& Stratton. 1983, pp. 575-625.

[6] Preisler HD. Acute myelocytic leukemia. In: Gunz FW, Henderson ES. (Eds). William Domashek and Frederick Gunz's leukemia, New York, Grune \& Stratton. 1983, pp. 627-661.

[7] Sethi VS, Thimmaiah KN. Structural studies on the degradation products of vincristine dihydrogen sulfate. Cancer Res. 1985; 45: 5386-5389. 
[8] Jelinska A, Zajac M, Cielelecka-Piontek J, Glab K, Tomaszewicz B, Krause A, Osczapowicz I, Wasowska M. Validation of a Stability Indicating LC-UV Method for [(N-Morpholine)methylene]daunorubicin Hydrochloride. Chromatographia 2008; 67: 107-111.

[9] Mitscher LA, Dutta A. Antitumor natural products, in: sixth ed., in: D.J. Abraham (Ed.), Berger's Medicinal Chemistry and Drug Discovery, vol. 5, John Wiley \& Sons, New Jersey, 2003, pp. 110-128.

[10] Zogotto G, Gatto B, Moro S, Sissi C, Palumbo M. Anthrcyclines: recent developments in their separation and quantitation. J Chromatogr B Biomed Sci Appl. 2001; 764(1-2): 161-171. [CrossRef]

[11] Kaushik D, Bansal G. Four new degradation products of doxorubicin: An application of forced degradation study and hyphenated chromatographic techniques. J Pharm Anal. 2015; 5(5): 285-295. [CrossRef]

[12] Vasiliu S, Bunia I, Racovita S, Neagu V. Adsorption of cefotaxime sodium salt on polymer coated ion exchange resin microparticles: Kinetics, equilibrium and thermodynamic studies. Carbohydr Polym. 2011; 85: 376-387. [CrossRef]

[13] Tapia C, Buckton G, Newton JM. Factors influencing the mechanism of release from sustained release matrix pellets, produced by extrusion/spheronisation. Int J Pharm. 1993; 92: 211-218. [CrossRef]

[14] Ferrero C, Massuelle D, Doelker E. Towards elucidation of the drug release mechanism from compressed hydrophilic matrices made of cellulose ethers. II. Evaluation of a possible swelling-controlled drug release mechanism using dimensionless analysis. J Control Release. 2010; 141(2): 223-33. [CrossRef]

[15] Gite S, Patravale V. Validation of RP-HPLC Method and Stress Degradation for the Combination of Metformin HCl, Atorvastatin Calcium and Glimepiride: Application to Nanoparticles. J Chromatogr Sci. 2015; 53(10): $1654-1662$. [CrossRef]

[16] Aksoy B, Küçükgüzel İ, Rollas S. Development and Validation of a Stability-Indicating HPLC Method for Determination of Ciprofloxacin Hydrochloride and its Related Compounds in Film-Coated Tablets. Chromatographia 2007; 66(1): 57-63.

[17] Blessy M, Ruchi DP, Prajesh NP, Agrawal YK. Development of forced degradation and stability indicating studies of drugs - A review. J Pharm Anal. 2014;4(3) 159-165. 